\title{
Vertical-cavity surface-emitting laser vapor sensor using swelling polymer reflection modulation
}

\author{
Ansbæk, Thor; Nielsen, Claus Højgård; Dohn, Søren; Larsson, David; Chung, II-Sug; Yvind, Kresten
}

Published in:

Applied Physics Letters

Link to article, DOI:

$10.1063 / 1.4754291$

Publication date:

2012

Document Version

Publisher's PDF, also known as Version of record

Link back to DTU Orbit

Citation (APA):

Ansbæk, T., Nielsen, C. H., Dohn, S., Larsson, D., Chung, I-S., \& Yvind, K. (2012). Vertical-cavity surfaceemitting laser vapor sensor using swelling polymer reflection modulation. Applied Physics Letters, 101(14), 143505. https://doi.org/10.1063/1.4754291

\section{General rights}

Copyright and moral rights for the publications made accessible in the public portal are retained by the authors and/or other copyright owners and it is a condition of accessing publications that users recognise and abide by the legal requirements associated with these rights.

- Users may download and print one copy of any publication from the public portal for the purpose of private study or research.

- You may not further distribute the material or use it for any profit-making activity or commercial gain

- You may freely distribute the URL identifying the publication in the public portal 


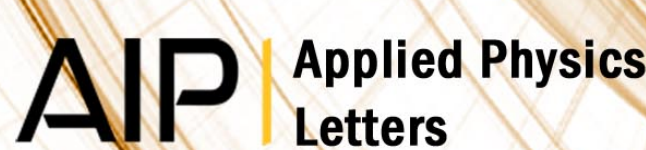

\section{Vertical-cavity surface-emitting laser vapor sensor using swelling polymer reflection modulation}

Thor Ansbæk, Claus H. Nielsen, Søren Dohn, David Larsson, II-Sug Chung et al.

Citation: Appl. Phys. Lett. 101, 143505 (2012); doi: 10.1063/1.4754291

View online: http://dx.doi.org/10.1063/1.4754291

View Table of Contents: http://apl.aip.org/resource/1/APPLAB/v101/i14

Published by the American Institute of Physics.

\section{Related Articles}

Wheatstone bridge piezoresistive sensing for bulk-mode micromechanical resonator

Appl. Phys. Lett. 101, 193505 (2012)

Distant mechanical sensors based on cholesteric liquid crystals

Appl. Phys. Lett. 101, 193503 (2012)

Differential reflectance modulation sensing with diffractive microstructures

Appl. Phys. Lett. 101, 191103 (2012)

Silicon nanowire based Pirani sensor for vacuum measurements

Appl. Phys. Lett. 101, 183506 (2012)

Note: Position self-sensing for piezoelectric actuators in the presence of creep and rate-dependent hysteresis

Rev. Sci. Instrum. 83, 116101 (2012)

\section{Additional information on Appl. Phys. Lett.}

Journal Homepage: http://apl.aip.org/

Journal Information: http://apl.aip.org/about/about_the_journal

Top downloads: http://apl.aip.org/features/most_downloaded

Information for Authors: http://apl.aip.org/authors

\section{ADVERTISEMENT}
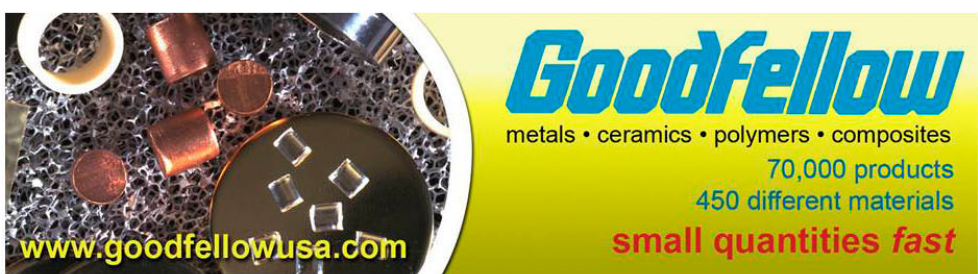


\title{
Vertical-cavity surface-emitting laser vapor sensor using swelling polymer reflection modulation
}

\author{
Thor Ansbæk, ${ }^{1}$ Claus H. Nielsen, ${ }^{2}$ Søren Dohn, ${ }^{2}$ David Larsson, ${ }^{1}$ II-Sug Chung, ${ }^{1}$ \\ and Kresten Yvind ${ }^{1, a)}$ \\ ${ }^{1}$ DTU Fotonik, Department of Photonics Engineering, Technical University of Denmark, Ørsteds Plads, \\ 2800 Kgs. Lyngby, Denmark \\ ${ }^{2}$ DTU Nanotech, Department of Micro- and Nanotechnology, Technical University of Denmark, Ørsteds Plads, \\ 2800 Kgs. Lyngby, Denmark
}

(Received 14 May 2012; accepted 7 September 2012; published online 3 October 2012)

\begin{abstract}
Vapor detection using a low-refractive index polymer for reflection modulation of the top mirror in a vertical-cavity surface-emitting laser (VCSEL) is demonstrated. The VCSEL sensor concept presents a simple method to detect the response of a sensor polymer in the presence of volatile organic compounds. We model the physics as a change in the top mirror loss caused by swelling of the polymer upon absorbing the target volatile organic compound. Further we show how acetone vapors at $82000 \mathrm{ppm}$ concentration can change the polymer coated VCSEL output power by $20 \mu \mathrm{W}$. (C) 2012 American Institute of Physics. [http://dx.doi.org/10.1063/1.4754291]
\end{abstract}

Vapor sensing is important in environmental and health monitoring where it is used to trace the concentration of a volatile organic compound (VOC), e.g., acetone, in time. ${ }^{1}$ Different transduction mechanisms for detection of VOCs has been proposed over the years such as polymer coated cantilevers, thin-film resistors, and optical fibers. ${ }^{2-4}$ Sensors using polymer coatings have the advantage that a unique finger-print response for each VOC can be obtained by using an array of different polymers. ${ }^{5,6}$ Vertical-cavity surfaceemitting lasers (VCSELs) are easily made into arrays and are thus a good candidate for the optical detection of such polymer coatings. We have earlier shown that self-mixing interference can advantageously be used for detection of cantilever deflections with responsivities up to $45 \mathrm{mV} / \mathrm{nm}^{7}$ This enables a more compact system than the optical lever method. ${ }^{8}$ In this paper we explain the physics of a VCSEL vapor sensor (Fig. 1), which avoids the cantilever altogether. ${ }^{9,10}$ By depositing the sensor polymer layer directly onto the VCSEL top mirror facet a device more feasible to manufacture is obtained without the need for precision alignment. The swelling caused by absorption of the target vapor changes both the polymer thickness and refractive index, leading to a modulation of the top mirror reflectance. This can be detected by monitoring the lasing wavelength, laser diode voltage, or output power. Here we present both experimentally and theoretically the detection of acetone vapor sorption by polystyrene, but any polymer that changes its optical thickness upon exposure to the target vapor can be used.

In order to model the sensor we use the standard laser equations. ${ }^{11}$ The laser power output can be written as

$$
P_{t}(\phi)=\eta_{d t}(\phi) \frac{h \nu}{q}\left[I-I_{t h}(\phi)\right]
$$

where $h$ is Planck's constant, $\nu$ the lasing frequency, $q$ the electron charge, $\eta_{d t}$ the differential quantum efficiency of

${ }^{\text {a)} E l e c t r o n i c ~ m a i l: ~ k r y v @ f o t o n i k . d t u . d k . ~}$ light output from the top mirror, $I$ the drive current, and $I_{t h}$ the threshold current. In Eq. (1) it is indicated that the power depends on the optical propagation phase $\phi=\frac{2 \pi}{\lambda_{0}} n_{p} t$ of the sensing polymer of thickness $t$ and refractive index $n_{p}$. From transfer matrix theory the mirror loss for a DBR stack with a swelling polymer coating can be found to be

$$
\alpha_{m}(\phi)=\frac{1}{L} \ln \left\{\frac{n_{A}+\left(n_{B}(\phi)-n_{A}\right) \sin ^{2}(\phi)}{n_{C}+\left(n_{D}(\phi)-n_{C}\right) \sin ^{2}(\phi)}\right\},
$$

where

$$
n_{A}=\left(n_{s}\left(\frac{n_{L}}{n_{H}}\right)^{2 N}-n_{0}\right)^{2} n_{C}=\left(n_{s}\left(\frac{n_{L}}{n_{H}}\right)^{2 N}+n_{0}\right)^{2},
$$

$n_{B}=\left(\frac{n_{s} n_{0}}{n_{p}}\left(\frac{n_{L}}{n_{H}}\right)^{2 N}-n_{p}\right)^{2} n_{D}=\left(\frac{n_{s} n_{0}}{n_{p}}\left(\frac{n_{L}}{n_{H}}\right)^{2 N}-n_{p}\right)^{2}$,

where $n_{s}$ is the refractive index of the substrate, $n_{L}$ and $n_{H}$ are the low and high refractive index of the DBR, $n_{0}$ the

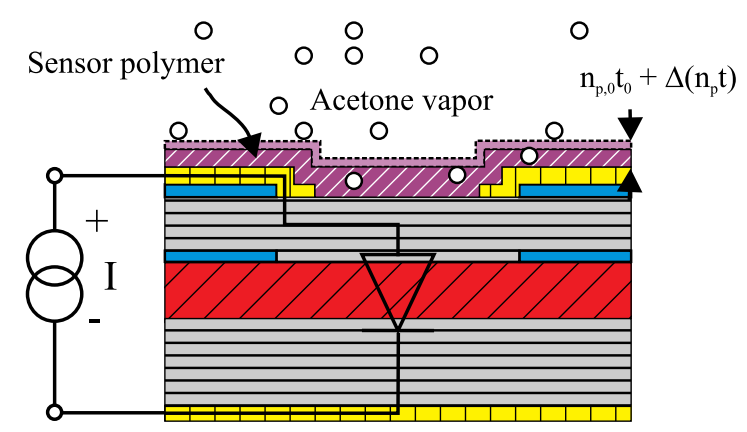

FIG. 1. Schematic drawing of the VCSEL sensor with the swelling polymer (inverted cross-hatch) of optical thickness $n_{p, 0} t_{0}$ plus increment $\Delta\left(n_{p} t\right)$, top and bottom mirror (horizontal hatch), electrical contacts (vertical hatch), pn-junction active medium (cross-hatch), and electrical insulator (solid). 
refractive index of air, and $n_{p}$ the refractive index of the polymer. For a zero thickness $\phi=0$ the mirror loss as defined in Eq. (2) is simplified to the expected result for a DBR mirror. The change in mirror loss changes the differential quantum efficiency according to

$$
\eta_{d t}(\phi)=\eta_{i} F_{t}(\phi) \frac{\alpha_{m}(\phi)}{\left\langle\alpha_{i}\right\rangle+\alpha_{m}(\phi)},
$$

where $\eta_{i}$ is the internal quantum efficiency, $F_{t}$ the fractional output of the top mirror, and $\left\langle\alpha_{i}\right\rangle$ the total cavity loss. Assuming a logarithmic gain-current relation the threshold carrier density depends exponentially on the mirror loss as

$$
N_{t h}(\phi)=N_{t r} \exp \left\{\frac{\left\langle\alpha_{i}\right\rangle+\alpha_{m}(\phi)}{N_{w} \Gamma_{1} g_{0}}\right\},
$$

where $N_{t r}$ is the transparency carrier density, $N_{w}$ the number of quantum wells, $\Gamma_{1}$ the single-well confinement factor, and $g_{0}$ the gain coefficient. ${ }^{11}$ Thus the threshold current also depends exponentially on the mirror loss as

$$
I_{t h}(\phi)=\frac{q N_{w} V_{1}}{\eta_{i}}\left[B N_{t h}(\phi)^{2}+C N_{t h}(\phi)^{3}\right],
$$

where $V_{1}$ is the single-well volume. Equations (1)-(7) describe the response of the VCSEL to a change in the polymer optical thickness or phase $\phi$. From taking the derivative of Eq. (1) with respect to the phase $\phi$ it is found that the term containing $\frac{\partial I_{h} h}{\partial \phi}$ is of opposite sign to that containing $\frac{\partial \eta_{d t}}{\partial \phi} .{ }^{12}$ Hence in order to operate at maximum responsivity the laser drive current is set close to $I_{t h}$, such that the contribution of the change in $\eta_{d t}$ becomes negligible. ${ }^{10}$ Equation (2) shows that the mirror loss depends on the sine to the phase, and therefore the optical film thickness should be different from that of an anti-reflection coating, $n_{p} t=\frac{\lambda_{0}}{4}$, as there the sensitivity of the sensor is zero. To model the change in $\phi$ we assume a swelling type behavior. It has been shown that the optical thickness, $n_{p} t$, of the polymer can be related to the acetone partial pressure through the theory of Flory-Huggins sorption. ${ }^{13}$ The degree of swelling, $\alpha$, as function of the acetone partial pressure, $p$, normalized to the saturation pressure, $p_{\mathrm{svp}}$, is given by

$$
\frac{p}{p_{\mathrm{svp}}}=\left(1-\frac{1}{\alpha}\right) \exp \left\{\frac{1}{\alpha}+\frac{\chi}{\alpha^{2}}\right\}
$$

where $\chi$ is the Flory-Huggins interaction parameter. ${ }^{13}$ We use the estimate $\chi=0.8$ from the analysis carried out by Mönch et al. on the transmittance of a polystyrene/polymethylmethacrylate optical Bragg filter. ${ }^{13}$ The thickness $t$ of the swollen polymer

$$
t(p)=\alpha(p) t_{0}
$$

depends on $\alpha$ and the initial thickness $t_{0} .{ }^{13,14}$ The refractive index of the polymer, $n_{p}$, depends on $\alpha$ as given by LorentzLorenz theory

$$
\frac{n_{p}^{2}-1}{n_{p}^{2}+2}=\frac{\alpha-1}{\alpha} \frac{n_{s}^{2}-1}{n_{s}^{2}+2}+\frac{1}{\alpha} \frac{n_{p, 0}^{2}-1}{n_{p, 0}^{2}+2},
$$

TABLE I. Laser parameters used in the simulation.

\begin{tabular}{lccc}
\hline \hline Parameter & Value & Unit & Comment \\
\hline$\lambda_{0}$ & 850 & $\mathrm{~nm}$ & GaAs MQW \\
$\Gamma g_{0}$ & 52.5 & $\mathrm{~cm}^{-1}$ & \\
$N_{t r}$ & $2.6 \times 10^{18}$ & $\mathrm{~cm}^{-3}$ & Ref. 11 \\
$N_{w}$ & 3 & & Ref. 15 \\
$L$ & 1.2 & $\mu \mathrm{m}$ & \\
$V$ & $1 \times 10^{-13}$ & $\mathrm{~cm}^{-3}$ & \\
$\left\langle\alpha_{i}\right\rangle$ & 16 & $\mathrm{~cm}^{-1}$ & Fitted \\
$\eta_{i}$ & 0.8 & & Ref. 11 \\
$B$ & $0.8 \times 10^{-10}$ & $\mathrm{~cm}^{3} \mathrm{~s}^{-1}$ & Ref. 11 \\
$C$ & $4.5 \times 10^{-34}$ & $\mathrm{~cm}^{3} \mathrm{~s}^{-1}$ & Fitted \\
$I$ & $1.1 I_{\text {th }}$ & $\mathrm{mA}^{-1}$ & \\
$N_{\text {top }} / N_{\text {bottom }}$ & $23 / 32$ & & Ref. 15 \\
$p_{s v p}$ & 0.24 & $\mathrm{~atm}$ & \\
$\chi$ & 0.8 & & Ref. 13 \\
$n_{\mathrm{s}}$ & 1.356 & & Measured \\
$n_{\mathrm{p}, 0}$ & 1.614 & & \\
$t$ & 200 & $\mathrm{~nm}$ & \\
\hline \hline
\end{tabular}

where $n_{s}$ is the solvent refractive index and $n_{p, 0}$ is the polymer refractive index. ${ }^{13}$ The refractive index decreases as the thickness increases, which is due to the lower refractive index of the absorbed vapor. The output power of the VCSEL was simulated using Eqs. (1)-(10) together with the parameters in Table I. We have chosen parameters representative for a GaAs quantum well VCSEL to model the response. ${ }^{15}$ For the parameters $C$ and $\left\langle\alpha_{i}\right\rangle$ to be reasonable, they have been fitted to the laser diode used in the experiment. In the model the thickness has been set to a value slightly above $\phi=\pi / 2$. In Fig. 2 the computed laser diode power (dashed line) is shown as a function of time. The output power is seen to increase for an increasing acetone concentration. Not shown in the graph, the model predicts decreasing $I_{t h}$ and $\eta_{d t}$, which causes the output power to increase at constant current.

Two single-mode $850 \mathrm{~nm}$ VCSEL diodes (Finisar $^{\circledR}$ HFE4093-332) were used for the experiment: (1) one reference, (2) another coated with $80 \mathrm{~nm}$ polystyrene by plasma polymerization. ${ }^{16}$ The thickness was measured on a silicon

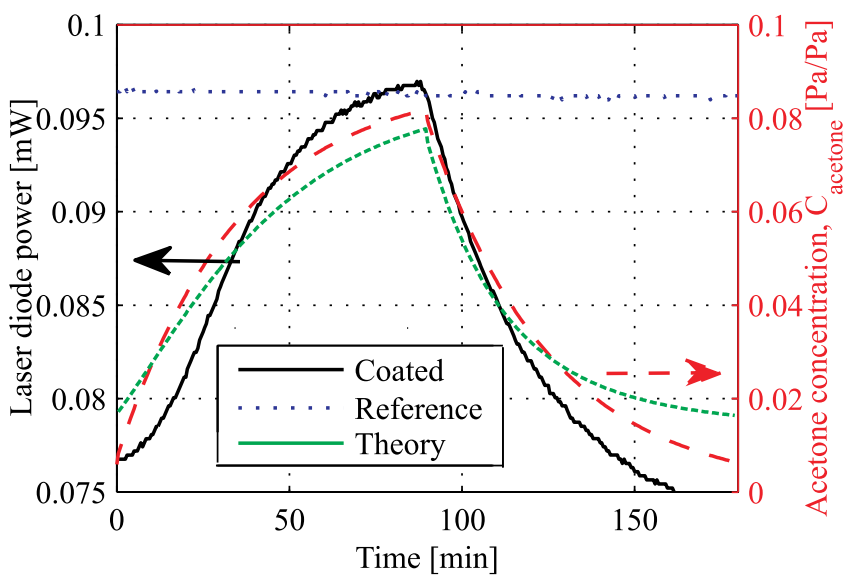

FIG. 2. Plot of the detected optical power of the coated VCSEL (solid line, left axis), reference VCSEL (dotted line), and the acetone concentration (dashed line, right axis) versus time. The laser drive current is $I=1.25 \mathrm{~mA}$ or $1.1 I_{t h}$. 
wafer coated concurrently with the VCSEL. The response measurement was performed by flowing diluted acetone vapors through a measurement chamber at a constant pressure of 600 Torr. The measurement chamber had a volume of $1800 \mathrm{~cm}^{3}$ with a filling time constant of $36 \mathrm{~min}$ at a flow of $50 \mathrm{sccm}$. During response measurements the VCSEL forward bias current was swept from 2 to $0.5 \mathrm{~mA}$ at a sampling frequency of $33 \mathrm{mHz}$. The VCSEL output power was measured using $\mathrm{Si}$ photodiodes (Thorlabs ${ }^{\circledR}$ FDS100). The acetone response of the coated VCSEL for a single cycle $(90 \mathrm{~min}$ acetone flow, 90 min nitrogen flow) is seen in Fig. 2 together with the acetone concentration calculated based on the input flows and the chamber volume. ${ }^{10}$ The response of the coated VCSEL is seen to follow the acetone concentration both during filling the chamber with acetone and on purging the chamber with nitrogen. The response is $21 \mu \mathrm{W}$ for an acetone concentration of $82000 \mathrm{ppm}$. The polymer thickness was not optimized for responsivity, and the VCSEL could not be operated at high powers due to power roll-off at increasing currents. To estimate the sensitivity that could be achieved with this technique we consider the following ideal case. For a laser diode operated at $5 I_{\text {th }}$ with a $t=80 \mathrm{~nm}$ thick sensing polymer we get a responsivity of $2 \mathrm{nW} / \mathrm{ppm}$ at $P_{t, 0}=2 \mathrm{dBm}$ in the ppm acetone concentration range by using Eqs. (1)(10) together with Table I. The ratio of the responsivity to the detected optical power is around $-120 \mathrm{~dB}$ in the electrical domain. The sensitivity will depend on the noise floor as determined by the VCSEL in the case of the photodetection being shot noise limited. Typical values for the VCSEL relative intensity noise (RIN) are -120 to $-130 \mathrm{~dB} / \mathrm{Hz}$, and thus ppm sensitivity should in theory be achievable. The sensitivity then comes down to the responsivity of the polymer. From Eqs. (8)-(10) and Table I we calculate that the optical thickness changes less than $0.5 \mathrm{~nm}$ from $10 \mathrm{ppm}$ to $10000 \mathrm{ppm}$. This is in the order of the surface roughness of the polymer, and thus it can be expected that only the change in refractive index will contribute to the responsivity. Removing Eq. (9) from the model the responsivity becomes $1 \mathrm{nW} / \mathrm{ppm}$ which should still enable detection with ppm sensitivity. Detection of VOCs at ppm is demonstrated by mass sensing using polymer coated cantilevers. ${ }^{17}$

Fig. 3 shows $I_{t h}$ and $\eta_{d t}$ as extracted from the measured light-current characteristic. Both the differential quantum efficiency and threshold current are seen to decrease with increasing acetone concentration. Based on the model this can only be explained as the polymer optical thickness increasing away from $\phi=\pi / 2$. From Eqs. (5) and (7), the only factor that is in common for both $\eta_{d, t}$ and $I_{t h}$ is $\left\langle\alpha_{i}\right\rangle$ and $\alpha_{m}$. The internal loss $\left\langle\alpha_{i}\right\rangle$ goes into both the denominator of $\eta_{d t}$ and the nominator of $I_{t h}$ and thus cannot explain the change. Hence the polymer swelling upon absorbing the VOC cause a reflection modulation of $\alpha_{m}$.

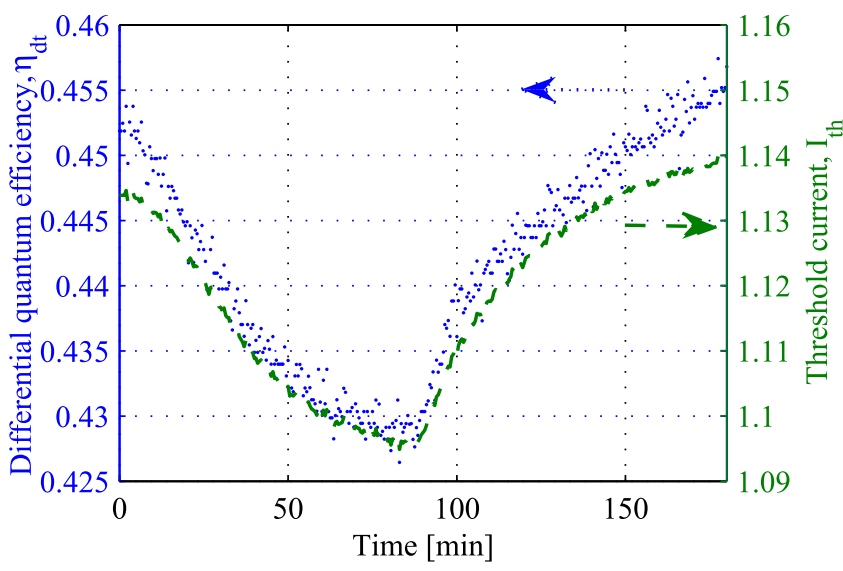

FIG. 3. Plot of the coated VCSELs differential quantum efficiency, $\eta_{d t}$ (solid line, left axis) and threshold current $I_{t h}$ (dashed line, right axis) versus time.

In summary we have shown that coating a VCSEL with a swelling polymer enables the transduction of VOCs. Specifically, detection of acetone has been demonstrated. The sensor can be made using standard VCSEL processing technology and the photodetector integrated epitaxially to make a compact, mass-producible sensor. Integrating the photodiode at the opposite side of the swelling polymer further has the advantage that a larger sensitivity can be achieved. ${ }^{12}$

The work was supported by the Danish strategic research council through the Nanonose project.

${ }^{1}$ H. Lord, Y. Yu, A. Segal, and J. Pawliszyn, Anal. Chem. 74, 5650 (2002).

${ }^{2}$ H. Jensenius, J. Thaysen, A. A. Rasmussen, L. H. Veje, O. Hansen, and A. Boisen, Appl. Phys. Lett. 76, 2615 (2000).

${ }^{3}$ J. Li, Y. Lu, Q. Ye, M. Cinke, J. Han, and M. Meyyappan, Nano Lett. 3, 929 (2003).

${ }^{4}$ D. K. C. Wu, B. T. Kuhlmey, and B. J. Eggleton, Opt. Lett. 34, 322 (2009).

${ }^{5}$ M. C. Lonergan, E. J. Severin, B. J. Doleman, S. A. Beaber, R. H. Grubbs, and N. S. Lewis, Chem. Mater. 8, 2298 (1996).

${ }^{6}$ T. S. Alstrøm, J. Larsen, C. H. Nielsen, and N. B. Larsen, Proc. SPIE 7697, 76970U (2010).

${ }^{7}$ D. Larsson, A. Greve, J. Hvam, A. Boisen, and K. Yvind, Appl. Phys. Lett. 94, 091103 (2009).

${ }^{8}$ S. Alexander, L. Hellemans, O. Marti, J. Schneir, V. Elings, P. K. Hansma, M. Longmire, and J. Gurley, J. Appl. Phys. 65, 164 (1989).

${ }^{9}$ C.-L. Shieh and D. E. Ackley, U.S. patent 5,331,658 (1994).

${ }^{10}$ T. Ansbæk, C. H. Nielsen, N. B. Larsen, S. Dohn, A. Boisen, I.-S. Chung, D. Larsson, and K. Yvind, Proc. SPIE 7615, 76150A (2010).

${ }^{11}$ L. A. Coldren and S. W. Corzine, Diode Lasers and Photonic Integrated Circuits (John-Wiley and Sons, New York, 1995).

${ }^{12}$ D. Larsson, K. Yvind, I.-S. Chung, and J. Hvam, Photon. Tech. Lett. 22, 667 (2010).

${ }^{13}$ W. Mönch, J. Dehnert, E. Jaufmann, and H. Zappe, Appl. Phys. Lett. 89, 164104 (2006).

${ }^{14}$ R. Toomey, D. Freidank, and J. Rühe, Macromolecules 37, 882 (2004).

${ }^{15}$ P. Westbergh, J. S. Gustavsson, A. Haglund, M. Skold, A. Joel, and A. Larsson, IEEE J. Sel. Top. Quantum Electron. 15, 694 (2009).

${ }^{16} \mathrm{~B}$. Winter-Jensen and K. West, U.S. patent 0,202,612 (2007).

${ }^{17}$ D. Lange, C. Hagleitner, A. Hierlemann, O. Brand, and H. Baltes, Anal. Chem. 74, 3084 (2002). 